\begin{tabular}{lcl}
\hline Jurnal Teknologi Kimia Unimal & $\begin{array}{l}\text { Jurnal } \\
\text { Teknologi } \\
\text { Kimia } \\
\text { Unimal }\end{array}$ \\
\hline http://ft.unimal.ac.id/teknik_kimia/jurnal & $\begin{array}{l}\text { Unimal } \\
\end{array}$ & \\
\hline
\end{tabular}

\title{
PEMANFAATAN LIMBAH KULIT PISANG BARANGAN SEBAGAI BAHAN PEMBUATAN PUPUK CAIR
}

\author{
Nasrun, Jalaluddin, Herawati \\ Jurusan Teknik Kimia Fakultas Teknik Universitas Malikussaleh \\ email: nasrun@unimal.ac.id
}

\begin{abstract}
Abstrak
Pupuk cair merupakan pupuk yang bahan dasarnya berasal dari hewan atau tumbuhan yang sudah mengalami fermentasi dan bentuk produknya berupa cairan. Kulit pisang barangan salah satu bahan dasar yang dinggunakan untuk pembuatan pupuk cair karena mengandung unsur mikro N, P dan K. Oleh karena itu dilakukan penelitian untuk mengetahui unsur hara yang terkandung dalam pupuk cair dari kulit pisang barangan. Penelitian ini dilakukan dengan mencampurkan molase, aquadest, air, dan Efektivitas Mikroorganisme (EM4) dengan variable tetap yang dinggunakan adalah kulit piang barangan 1500 gram Sedangkan variabel bebas yang dipakai pada penelitian ini waktu inkubasi (7 hari, 14 hari, 21 hari), Variasi molase $(80 \mathrm{ml,90} \mathrm{ml,100} \mathrm{ml),} \mathrm{dan} \mathrm{Variasi} \mathrm{EM4}$ $(200 \mathrm{ml}, 400 \mathrm{ml}, 600 \mathrm{ml})$. Hasil penilitian menunjukkan bahwa variabel terbaik pada waktu fermentasi 21 hari dengan volume EM-200 $\mathrm{ml}$ dengan volume molase- $80 \mathrm{ml}$ yaitu pH 5,10, unsur Nitrogen 1,54 \% dan Kalium 0,60\%.
\end{abstract}

Kata kunci: pupuk cair, fermentasi, pisang barangan, rendemen, nitrogen

\section{Pendahuluan}

Buah pisang biasanya dikonsumsi secara tidak langsung yakni dengan mengolahnya terlebih dahulu agar menjadi berbagai produk yang memiliki nilai jual yang lebih tinggi dibandingkan tanpa ada proses pengolahan. Dari berbagai proses pengolahan tersebut, tentunya menghasilkan limbah yang salah satunya adalah limbah kulit pisang. Limbah kulit pisang biasanya terbuang begitu saja atau hanya sebagai bahan pakan ternak yang secara ekonomis tidak termanfaatkan secara efisien. 
Berdasarkan latar belakang tersebut maka penulis berinisiatif untuk mengolahnya menjadi produk teknologi tepat guna berupa pembuatan pupuk cair, dikarenakan limbah kulit pisang mengandung unsur makro $N, P, K$ yang masingmasing berfungsi untuk pertumbuhan dan perkembangan buah dan batang. Selain itu juga mengandung unsur mikro $\mathrm{Ca}, \mathrm{Mg}, \mathrm{Na}, \mathrm{Zn}$ yang dapat berfungsi untuk kekebalan dan pembuahan pada tanaman agar dapat tumbuh secara optimal sehingga berdampak pada jumlah produksi yang maksimal (Hery, 2011).

Pada penelitian ini penulis juga menggunakan EM4. Penggunaan Effective Microorganisme (EM4) dalam mempercepat pembuatan pupuk cair dianggap sebagai teknologi karena bertujuan untuk mempercepat proses fermentasi. Effective Microorganisme merupakan kultur campuran berbagai jenis mikroorganisme yang bermanfaat (bakteri fotosintetik, bakteri asam laktat, ragi aktinomisetes dan jamur fermentasi) yang dapat meningkatkan keragaman mikroba tanah. Pemanfaatan EM4 dapat memperbaiki pertumbuhan dan hasil tanaman.

Berdasarkan latar belakang di atas, dapat dirumuskan masalah yaitu bagaimana proses pembuatan pupuk cair dari limbah kulit pisang barangan dan bagaimana pengaruh penggunaan Effective Microorganisme (EM4) terhadap pupuk cair dari limbah kulit pisang barangan. Berdasarkan perumusan masalah tersebut, maka tujuan penelitian ini adalah mengkaji pengaruh waktu perendaman dan volume Effective Microorganisme (EM4) terhadap kualitas pupuk cair dari limbah kulit pisang barangan.

\section{Bahan dan Metode}

Adapun bahan dan peralatan yang digunakan dalam penelitian ini adalah kulit pisang barangan, molase, EM4, aquadest, pH meter, timbangan, galon air, pipet ukur, selang, gelas ukur, dan blender.

\subsection{Pembuatan Pupuk Cair}

Limbah kulit pisang yang telah dipersiapkan ditimbang seberat 1500 gr. Kemudian dicacah dengan belender hingga halus. Kemudian dimasukkan masingmasing 500 gr kedalam 3 buah galon air yang berukuran 5 liter. Untuk galon 
pertama ditambahkan EM4 : $200 \mathrm{ml}$; Aquadest : $800 \mathrm{ml}$ dan Molase : $80 \mathrm{ml}$, galon kedua EM4 : $400 \mathrm{ml}$; Aquadest : $700 \mathrm{ml}$ dan Molase : $90 \mathrm{ml}$ dan galon ketiga EM4 : $600 \mathrm{ml}$; Aquadest : $600 \mathrm{ml}$ dan Molase : $100 \mathrm{ml}$. Kemudian diaduk sampai campuran di dalam Galon homogen dan ukur $\mathrm{pH}$ campuran. Lalu ditutup galon dengan penutup yang telah di pasang dengan selang plastik. Kemudian selang plastik di hubungkan ke gelas ukur yang terisi air penuh. Selanjutnya inkubasi dan lakukan pengamatan 7, 14, 21 hari hingga diperoleh cairan kental atau pupuk organik cair di dasar galon dan gas yang dihasilkan di dalam Gelas Ukur konstan. Pupuk organik cair di keluarkan melalui kran yang telah terpasang di galon. Kemudian analisa kandungan rasio $\mathrm{C} / \mathrm{N}, \mathrm{pH}$ dan rendemen.

\section{Hasil dan Diskusi}

\subsection{Pengaruh Waktu Fermentasi terhadap pH}

Pengaruh waktu fermentasi terhadap pH ditunjukkan oleh Gambar 1.

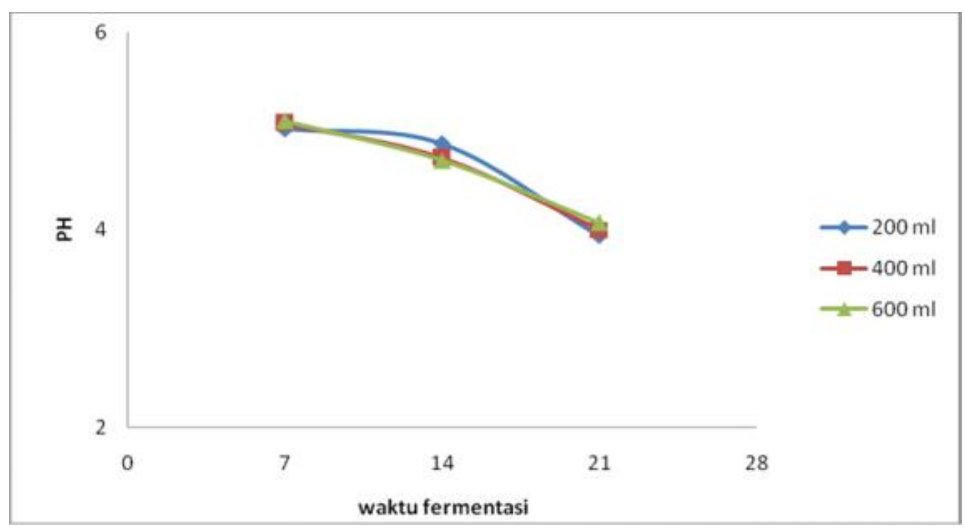

Gambar 1 Pengaruh waktu fermentasi terhadap pH

Gambar 1 menunjukkan bahwa pada penggunaan limbah kulit pisang barangan sebanyak 500 gram dan EM4 sebanyak $200 \mathrm{ml}$, aquadest $800 \mathrm{ml}$ dan molase $80 \mathrm{ml}$, dengan waktu inkubasi 7 hari $\mathrm{pH}$ yang didapatkan sebesar 5,02. Kemudian pada inkubasi 14 hari dengan menggunakan EM4 sebanyang 400 ml, aquades sebanyak $700 \mathrm{ml}$ dan molase $90 \mathrm{ml} \mathrm{pH}$ yang didapatkan sebesar 4,87. Pada penelitian ini menunjukkan bahwa semakin banyak air yang digunakan maka $\mathrm{pH}$ yang didapatkan semakin tinggi dan semakin lama waktu inkubasi maka $\mathrm{pH}$ yang dihasilkan juga semakin tinggi, hal ini desebabkan oleh pengaruh beberapa 
faktor pertumbuhan mikro organisme seperti suhu yang tidak stabil dan kondisi lingkungan.

\subsection{Pengaruh Penambahan EM4 terhadap Rendemen}

Pengaruh penambahan efektif mikroorganisme terhadap rendemen dapat dilihat pada Gambar 2.

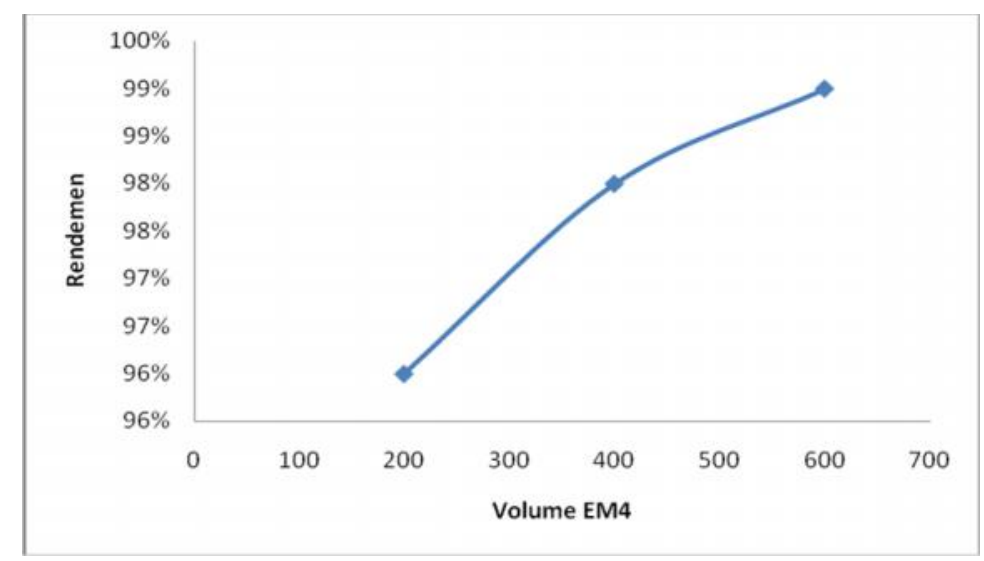

Gambar 2 Pengaruh penambahan EM4 terhadap rendemen

Gambar 2 memperlihatkan bahwa pada galon pertama dengan berat limbah kulit pisang barangan 500 gram, aquades $800 \mathrm{ml}$, EM4 $200 \mathrm{ml}$ dan molase $80 \mathrm{ml}$, rendemen yang didapatkan sebesar $96 \%$, kemudian pada galon ke 2 dengan menggunakan kulit pisang barangan 500 gram, aquades 700 ml, EM4 400 $\mathrm{ml}$, dan molase sebanyak $90 \mathrm{ml}$, rendemen yang didapatkan sebesar $98 \%$. Rendemen terbesar didapatkan pada galon ke 3 dengan berat limbah kulit pisang barangan sebanyak 500 gram, aqudes $600 \mathrm{ml}$, EM4 $600 \mathrm{ml}$ dan molase sebanyak $100 \mathrm{ml}$ yaitu rendemen yang didapatkan sebesar 99\%. Hal ini menunjukkan bahwa semakin banyak EM4 yang dinggunakan maka rendemen yang didapatkan juga semakin besar yang diakibatkan oleh pembelahan sel oleh mikroorganisme semakin banyak sehingga hasil yang didapatkan juga semakin besar.

\subsection{Pengaruh Waktu Fermentasi terhadap Kadar Nitrogen (N)}


Pengaruh waktu fermentasi terhadap kadar nitrogen (N) dapat dilihat pada Gambar 3.

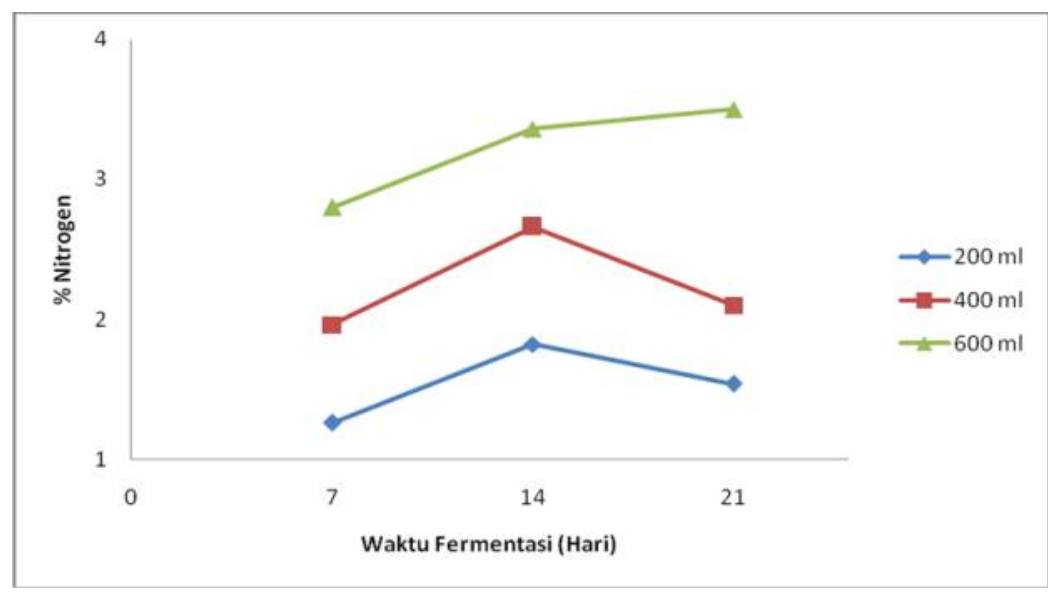

Gambar 3 Pengaruh waktu fermentasi terhadap \% nitrogen

Gambar 3 menunjukkan bahwa kadar nitrogen yang diperoleh pada galon pertama dengan menggunakan EM-4 $200 \mathrm{ml}$, aquadest $800 \mathrm{ml}$ dan molase $80 \mathrm{ml}$, dan waktu fermentasi 7, 14 dan 21 hari, kadar nitrogen yang diperoleh masing-masing sebesar $1,26 \%, 1,82 \%$ dan $1,42 \%$. Kadar nitrogen terendah didapatkan pada volume EM-4 $200 \mathrm{ml}$.

Hal ini disebabkan karena dalam waktu fermentasi 7 hari terjadi pertumbuhan mikroorganisme fase awal yang merupakan periode adaptasi yakni sejak inokulasi pada medium dilakukan, selama fase awal ini massa sel dapat berubah tanpa adanya perubahan jumlah sel yang terlalu signifikan. Hal ini dapat berpengaruh terhadap tanaman, karena bila kekurangan kadar nitrogen tumbuhan dapat menyebabkan daun kerdil, daun tampak kekuning-kuningan dan sistem perakaran yang terbatas (Tejasarwana, 1998). Sedangkan pada galon ke dua dengan menggunakan EM-4 $400 \mathrm{ml}$, aquadest $700 \mathrm{ml}$ dan molase $90 \mathrm{ml}$, dengan waktu fermentasi 7, 14 dan 21 hari, kadar nitrogen yang didapat masing-masing sebesar $1,96 \%, 2,66 \%$ dan 2,10\%. Ini menunjukkan bahwa persen nitrogen yang didapatkan semakin tinggi. Hal tersebut disebabkan karena pertumbuhan mikroorganisme mengalami fase eksponensial yaitu terjadi pembelahan sel yang sangat cepat dan dengan kadar nitrogen yang didapatkan semangkin tinggi dapat 
berpengaruh pada tanaman karena bila kelebihan unsur hara nitrogen pada tumbuhan dapat mengakibatkan lambat panen, mudah rebah dan serangan terhadap hama atau penyakit. Sedangkan kadar nitrogen yang mendekati standar kandungan hara pada fermentasi 14 hari, kemidian pada nitrogen ke 21 hari kadar nitrogen yang diperoleh semakin menurun hal ini dipengaruhi oleh pertumbuhan mikro organisme dan nutrisi yang tersedia mulai berkurang dan sel mulai berhenti membelah diri atau sel hidup dan sel mati mulai mencapai kesetimbangan.

\subsection{Pengaruh Waktu Fermentasi terhadap Kadar Kalium Oksida $\left(\mathrm{K}_{2} \mathrm{O}\right)$}

Pengaruh waktu fermentasi terhadap kadar kalium oksida $\left(\mathrm{K}_{2} \mathrm{O}\right)$ dapat dilihat pada Gambar 4.

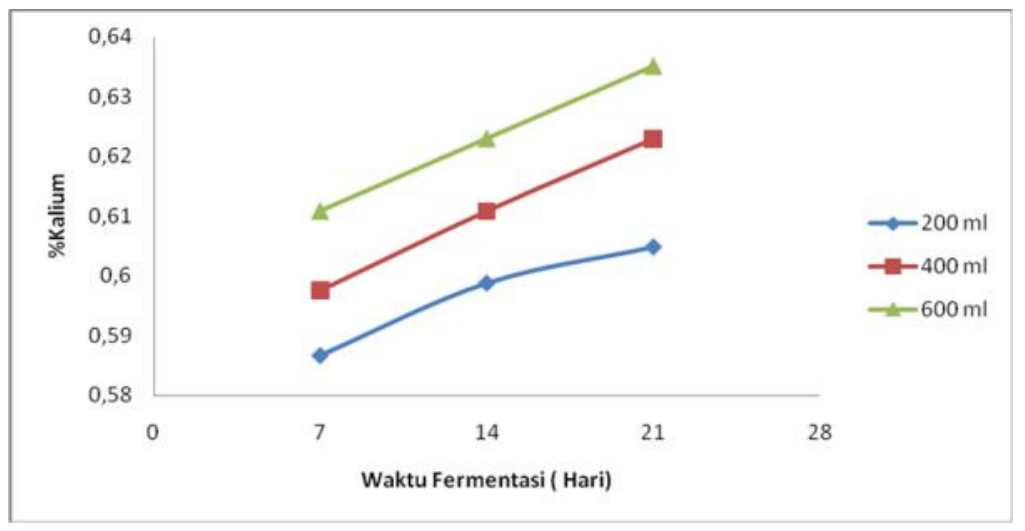

Gambar 4 Pengaruh waktu fermentasi terhadap kadar $\mathrm{K}_{2} \mathrm{O}$

Gambar 4 memperlihatkan bahwa kadar $\mathrm{K}_{2} \mathrm{O}$ yang tinggi diperoleh pada hari ke21, pada volume EM-4 $600 \mathrm{ml}$ yaitu 0,635\%. Hal ini disebabkan pada waktu 18 hari dengan volume aktivator $600 \mathrm{ml}$ merupakan proses terjadinya pembelahan sel yang sempurna. Akan tetapi dapat kita lihat juga bahwa semakin lama waktu fermentasi maka hasil yang didapat semakin meningkat, seperti yang terlihat pada Gambar 4 pada volume EM-4 200 ml dengan waktu yang berbeda yaitu 7 hari kadar $\mathrm{K}_{2} \mathrm{O}$ adalah $0,586 \%$, hari ke 14 kadar $\mathrm{K}_{2} \mathrm{O}$ yang didapat yaitu $0,598 \%$, hari ke 21 kadar $\mathrm{K}_{2} \mathrm{O}$ yang dihasilkan yaitu $0,60 \%$. Meskipun kadar $\mathrm{K}_{2} \mathrm{O}$ yang didapat sudah memenuhi SNI tetapi kadarnya masih sangat rendah dibandingkan dengan pupuk cair organik yang dijual di pasaran. 


\section{Simpulan dan Saran}

\subsection{Simpulan}

Berdasarkan hasil penelitian maka dapat diambil kesimpulan sebagai berikut:

1. Kandungan N, P, dan K yang didapat sudah memenuhi SNI pupuk cair organik akan tetapi kandungannya masih sangat rendah dibanding dengan produk-produk pupuk organik cair yang dijual di pasaran.

2. Semakin lama waktu fermentasi dan semakin banyak volume EM4 yang digunakan semakin tinggi nilai $\mathrm{N}, \mathrm{P}$, dan $\mathrm{K}$ yang didapat.

3. Kandungan $\mathrm{pH}$ yang terbaik diperoleh pada waktu fermentasi 21 hari yaitu volume EM4 $200 \mathrm{ml}$ dengan molase $80 \mathrm{ml}$ dengan $\mathrm{pH}$ 5,1.

\subsection{Saran}

Penulis menyarankan untuk penelitian selanjutnya hendaknya dilanjutkan dengan menganalisa parameter dan bahan baku lainnya seperti parameter karbon, phosphor, dan $\mathrm{C} / \mathrm{N}$ dengan bahan baku sayur-sayuran.

\section{Daftar Pustaka}

Afifudin, Pengaruh Berbagai Aktivator Terhadap C/N Rasio Kompos Kotoran, Penerbit CV. Sinar Indah, Bogor, 2011.

Andhika Cahaya, Pembuatan kompos dengan Limbah Padat Organik (Sampah Sayuran dan Ampas Tebu), Tugas Akhir, Jurusan Teknik Kimia UNDIP, 2009.

Elmi Sundari, Ellyta Sari, Riko Rinaldo, Pembuatan Pupuk Organik Cair Menggunakan Bioaktivator Biosca dan EM4, Prosiding SNTK TOPI 2012, Pekanbaru 11 Juli 2012.

Endang Yulistiawati, Pengaruh Suhu dan C/N Rasio Terhadap Produksi Biogas Berbahan Baku Sampah, Skripsi S1, Jurusan Teknologi Pertanian IPB, 2008.

Esther L. Tobing, Studi Tentang Kandungan Nitrogen, Karbon (C) Organik dan C/N dari Kompos Tumbuhan Kembang Bulan (Tithonia diversifolia), 
Skripsi, Departemen Kimia, Fakultas Matematika dan Ilmu Pengetahuan Alam, Universitas Sumatera Utara, Medan, 2009.

Hadisuwito, S., Membuat Pupuk Kompos Cair. 394 Agromedia Pusaka, Jakarta. 2007

Hery, Kiat Pintar Memproduksi Kompas dengan Peguraian Sendiri, Yokyakarta Lily Publisher, 2011.

Indriyani, Y. H., Membuat Kompos Secara Kilat. Jakarta : PT. Penebar Swadaya, 2011.

Marsono dan Paulus., Pupuk Akar Jenis dan Aplikasi. Penebar Swadaya, Jakarta, 2001.

Murbondo, L., Pupuk Organik Padat, Pembuatan Aplikasi. Penebar Swadaya, Jakarta, 2004.

Purwendro.S.,dan Nur Hidayat, Mengolah Sampah Untuk Pupuk Dan Pestisida organik, Seri Agritekno, Penebar Swadaya, Jakarta, 2001.

Simamora, Suhut, dan Salundik., Meningkatkan Kualitas Kompos, Harian Analisa, Medan, 2006.

Yowono, D., Dengan Cara Aerob maupun Suntik menghasilkan kompos yang Berkualitas, Penebar Swadaya, Jakarta, 2006. 